\title{
ADVANCED GAS TUNGSTEN ARC WELDING (SURFACING) CURRENT STATUS AND APPLICATION
}

\author{
S. EGERLAND, J. ZIMMER, R. BRUNMAIER, R. NUSSBAUMER, G. POSCH and B. RUTZINGER \\ Fronius International GmbH, Wels, Austria. E-mail: egerland.stephan@fronius.com
}

\begin{abstract}
Gas Shielded Tungsten Arc Welding (GTAW) — a process well-known providing highest quality weld results joined though by lower performance. Gas metal arc welding is frequently chosen to increase productivity along with broadly accepted quality. Those industry segments, especially required to produce high quality corrosion-resistant surfacing, e.g. applying nickel-based filler materials, are regularly in consistent demand to comply with «zero defect» criteria. In this conjunction weld performance limitations are overcome employing advanced «hot-wire» GTAW systems. This paper, from a welding automation perspective, describes the technology of such devices and deals with the current status is this field, namely the application of dual-cathode hot-wire electrode GTAW cladding, considerably broadening achievable limits. 27 Ref., 2 Tables, 14 Figures.
\end{abstract}

Keywords : GTAW (cladding), single-cathode GTAW, hot-wire welding, dual-cathode GTAW

Arc welding, to the widest extent, is suggested utilised for fusion welding. The major remainder, i.e. weld surfacing, is supposed reasonably split into «hardfacing» and «corrosion-resistant» weld overlay $[1,2]$. Economic considerations drive manufacturers to apply high performance surfacing processes, such as submerged-arc welding or resistance electroslag welding. Although producing broadly acceptable quality, these processes are specifically limited respectively due to compulsory use of flux (limited out-of-position capabilities), high dilution, or undesirable aspect ratios.

Controlled gas metal arc welding processes (e.g. CMT method) have been introduced to the industry coping with dilution related issues, e.g. corrosion [3], and thereby partially replacing submerged-arc and resistance electroslag welding. Surfacing applications exist, however, defining «zero defect» criteria paramount to prevent complicated rework, sustainably assure highest surfacing performance and maintaining long-term component durability. Though joined by limited performance in arc efficiency and weld deposition rate, gas shielded tungsten arc welding (GTAW)

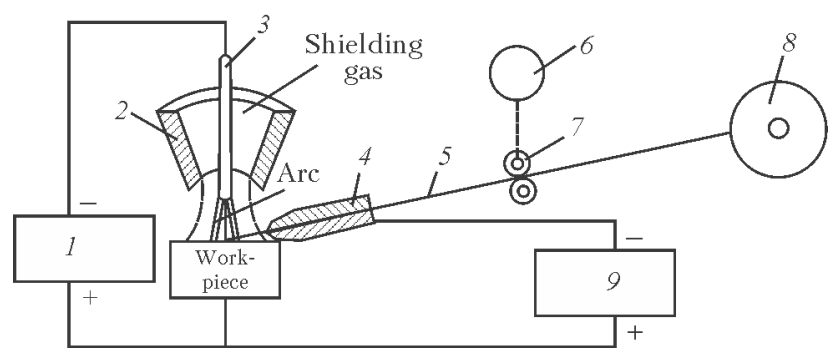

Figure 1. Schematic of hot-wire GTAW system [6]: 1 - GTAW power supply (CC mode); 2 - nozzle; 3 - tungsten electrode; 4 - contact tube; 5 - filler wire; 6 - wire feeder; 7 - feed rolls; 8 - wire reel; 9 - hot wire power supply (CV mode) is frequently applied in such cases. To overcome lack of performance, systems have been developed modifying the wire feeding process hereby leading to either «coldwire» or «hot-wire» GTAW. While the former was early revealing process instabilities and noticeably rather difficult deployable $[4,5]$, the latter appeared capable of tackling inconsistencies, mainly, by preheating the wire.

Manz [6] early described the advantages, e.g. a significant increase in weld deposition rate through beneficially using the resistive wire heating and, compared with cold-wire GTAW, hereby achieving wire feed rates 3 to 10 times faster into the weld pool [4]. Hot-wire GTAW systems continuously advanced are nowadays well-accepted because of providing user benefits $[2,7,8]$. Information on the operational relationship applying hot-wire and cold-wire GTAW is given in [6] and according to this author proper parameter set up would even allow the deposition of wire without any additional arc. This is due to electrical resistive heating of the wire of a specific composition and diameter according to [6]

$$
r^{2} R=I^{2} L \rho / d^{2}(\pi / 4) \text {, }
$$

where $\rho$ is the apparent resistivity of the wire material; $L$ is the effective wire extension length; and $d$ is the wire diameter. The energy required for melting the wire can be expressed as

$$
E_{\text {melt }}=H F \delta d^{2}(\pi / 4)
$$

where $H$ is the heat content of the liquid wire volume; $F$ is the wire feed rate; and $\delta$ is the apparent wire density.

Figure 1 adopted from [6] schematically depicts the hot-wire GTAW principle.

Wire feed rate can be computed as

$$
F=R^{2} L(E S) /\left(\pi d^{2} / 4\right) \text {. }
$$

$E S$ is here referred to as the "extension sensitivity constant» [6] dependent only on the wire material 
composition. Correspondingly, solving for the wire extension length, $L$ leads

$$
L=F\left(\pi d^{2} / 4\right)^{2} / I^{2}(E S) \text {. }
$$

$E S$ can be derived from equation

$$
E S=\rho / H \delta \text {. }
$$

The apparent resistivity $\rho$, i.e. the difference between melting and room temperature resistivity, can be approximated as

$$
\rho=\rho_{\text {melt }}-\rho_{\text {amb }} / \ln \left(\rho_{\text {melt }} / \rho_{\text {room }}\right),
$$

while the apparent wire material density $\delta$ can be obtained from equation

$$
\delta=\delta_{\text {melt }}-\delta_{\text {amb }} / \ln \left(\delta_{\text {melt }} / \delta_{\text {amb }}\right) .
$$

According to [6], ES is proportional to the $I^{2} R$ deposition rate value; thus, higher resistant wires comparably provide higher deposition rate versus lower resistivity electrodes.

Due to mechanised wire feeding, cold-wire GTAW provides relatively high deposition rates. Frequently joined by instabilities in supplying the wire electrode into the molten pool, however, it may cause irregular wire melting. Chilling phenomena are observed, degrading process stability and weld quality, regardless of whether the wire enters the melt pool either from the leading or trailing edge. The arc is required to melt both the base and the filler material which increases the risk for producing irregular weld beads.

Electrode preheating in hot-wire GTAW makes a considerable part of arc power unneeded to melt the wire. Maintaining an appropriate angle to enter the weld pool $\left(0 \leq 30 \leq 60^{\circ}\right)[4]$ the wire can be beneficially located at the trailing edge, close to but not directly interacting with the arc [5].

More recent developments eliminate the second power supply by involving two current control electronic circuits, the first of which provides constant voltage (CV) characteristics for filler wire heating, and the second circuit board provides constant current (CC) characteristics output for controlling the arc current [8]. Although claiming to significantly reduce the amount of equipment regularly needed for hot-wire GTAW, it remains unknown to the authors whether such machines have obtained considerable industrial application, especially for surfacing, that can prove advantageous over cold-wire GTAW because of both reducing penetration depth and dilution as to maintain process stability.

For hot-wire GTAW, Goldsberry [9] presumes that this technology in general has found just limited industrial application since invented in the 1960s. Hence specific studies were mainly conducted to understand phenomena connected to improving productivity, e.g. by involving two wires inductively heated and successfully electromagnetically controlling the weld pool volume in out of position fusion welding [10]. Hori et al. [11] have studied magnetic arc blow phenomena wellknown a major issue in employing hot-wire GTAW technology. The authors, who have developed a system to apply high frequency $(50-150 \mathrm{~Hz})$ pulsed current for pre-heating the wire, could overcome instabilities («arcing») caused by electromagnetic fields induced by the gas-shielded tungsten arc and acting on the wire as soon as being detached from the workpiece. Ueguri et al. [12] have tried to assess the optimum relation between welding current and melting rate using parts of the arc heat for wire pre-heating. An increase of travel speed was found mainly permitted by the enlargement of the weld pool width; weld current was found limiting the wire feed rate, following an almost linear relationship with the wire heating current. Also for fusion welding application, Yamamoto et al. [13] have developed «ultra-high-speed» hot-wire GTAW process. To achieve high travel speed and acceptable quality it was found that the wire pre-heating temperature is the most important parameter. Directly related to [13], Shinozaki et al. [14] have thoroughly studied phenomena caused by either the wire temperature and arc thermal input. The authors concluded that filler wire melting is mainly affected by wire pre-heating temperature and base metal melting is mainly caused by the welding arc.

Hot-wire GTAW cladding automation. Welding automation beneficially contributes in raising productivity and efficiency, even when employing single hot-wire GTAW surfacing. Advanced equipment (Figure 2) can be used, e.g. for internal and external GTAW cladding application.

Separately feeding two electrically insulated wires to the weld pool produced by one tungsten electrode, successfully increases productivity. Appropriate welding torches suitable for automated internal or external hot-wire GTAW weld overlay have been developed for industrial application and overcome «single wire» limitations [2]. Applying such equipment allows economically cladding heavy components and simultaneously meet highest quality requirements, i.e. «zero defect» criteria along with providing low dilution ratios.

Multi-cathode GTAW. Increasing GTAW performance or weld deposition rate is regularly joined by increasing welding current, rising arc force or arc pressure, respectively $[15,16]$. The latter again is susceptible to cause weld defects, such as undercut or bead humping [17]. To cope with these limitations Yamada in the late 1990s [18] developed and patented [19] a novel high-efficiency GTAW method. Both electrodes, independently operated by two power supplies and electrically insulated to each other, are paired in one welding torch. Feeding hot wire to the weld pool allows increasing the weld performance, i.e. weld deposition rate, in production of large $9 \% \mathrm{Ni}$-steel storage tanks [20]. Electrode geometry and adjustment are stated among the specifics of this method. Multi-cathode GTAW (Figure 3,a) has early been tested to improve both process efficiency and weld quality.

Norrish [21] describes multi-cathode GTAW capable of significantly increasing travel speed and, by 


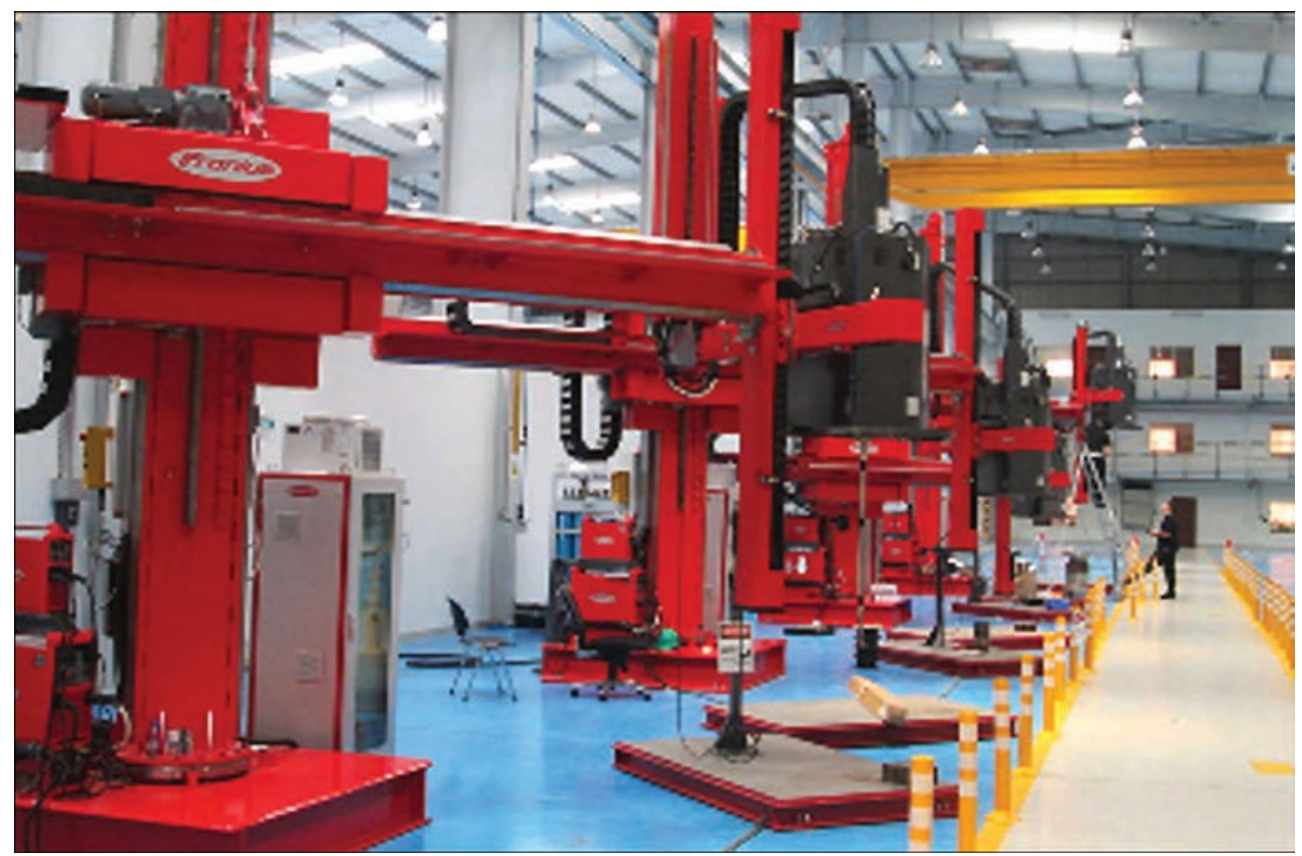

Figure 2. Endless Torch Rotating ETR ${ }^{\circledR}$ systems lined up for internal borehole GTAW cladding

elongating the weld pool, preventing weld defects such as undercut. Figure 3, $b$ plots welding speed over current in deploying single- and multi-cathode GTAW. Considerable differences become noticeable through beneficially raising the number of cathodes. Undesirable but possible arc deflection between the electrodes is overcome by e.g. employing high-frequency pulsing or magnetic arc stabilisation [21].

Dual-cathode GTAW. Zhang et al. [22] studied the physical phenomena of twin TIG welding, i.e. GTAW employing two electrodes in one welding torch. The authors suggested the Lorentz force to attract both arcs hereby forming a single arc whose pressure gradient is considerably lower versus single-electrode GTAW process.

The attracting force can be calculated as follows [22]:

$$
F=k \frac{I_{1} I_{2}}{L},
$$

where $k$ is the constant; $I_{1}$ and $I_{2}$, respectively, is the welding current for cathodes 1 and 2 ; and $L$ is the dis-

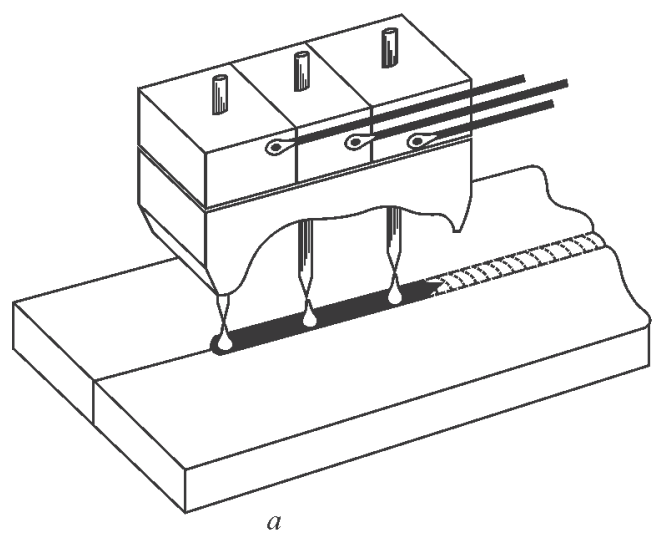

tance between both electrodes. $F$ is proposed increasing with rising current $I$ and decreasing with rising distance $L$. It was attempted to evaluate these relationships and the resulting phenomena effects especially on arc pressure. It was found the latter decreases in dual-cathode GTAW due to a broader area covered by the coupled arc approaching an elliptic cross-section.

Figure 4, $a$ [23], for single-cathode welding reveals the arc pressure steeply rising at the arc centre with increasing currents. Figure $4, b$ again for dual-cathode GTAW shows the pressure level flattened and more broadly distributed around the arcs attracted.

Surfacing in general requires low dilution rates to maintain the deposited weld metal properties, e.g. corrosion resistance; weld pool depression again is considered a function of welding current height [16]. Leng et al. [23] connected to [22] have thoroughly studied the relationships between current height and its influence on arc pressure distribution in dual-cath-

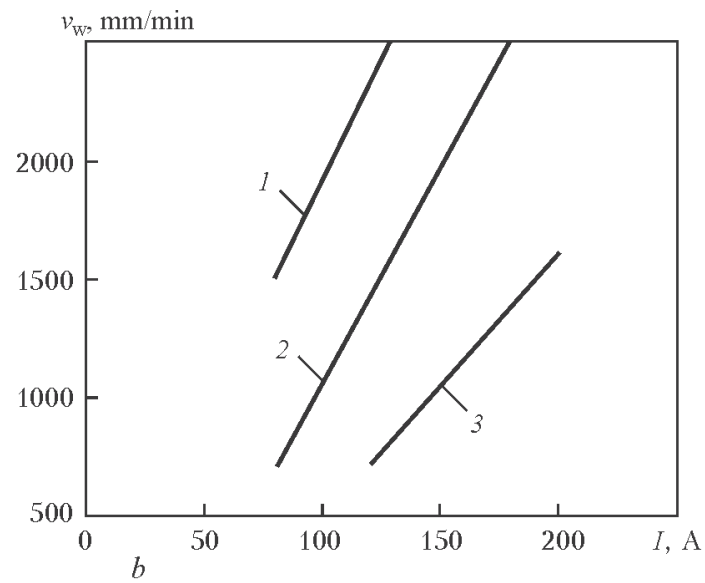

Figure 3. Schematic of multi-cathode GTAW (a), and comparison of welding speed $(b)$ for complete penetration with AISI 304 stainless steel wire of $1.2 \mathrm{~mm}$ diameter: 1 - three-cathode; 2 — two-cathode; 3 - single-electrode GTAW [21] 


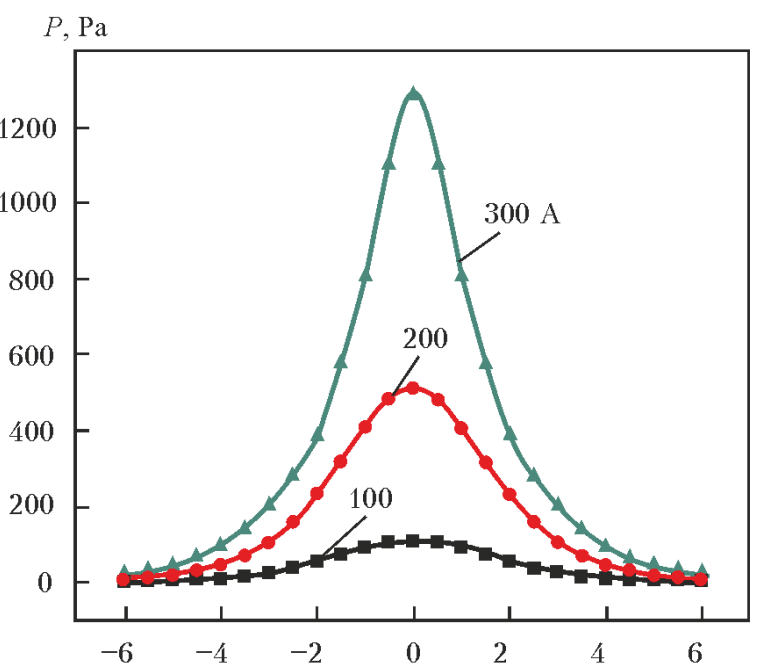

$a$

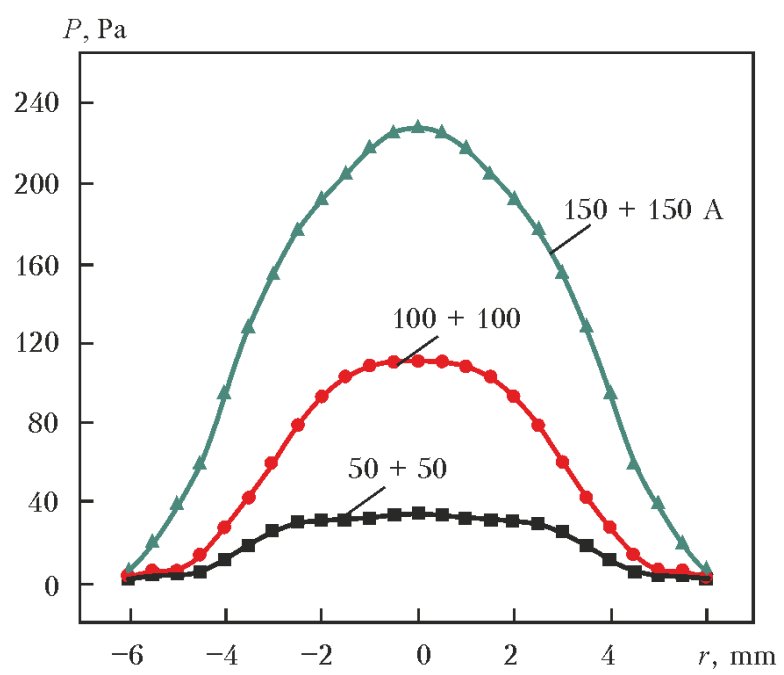

$b$

Figure 4. Arc pressure measured for single- $(a)$ and dual-cathode (b) GTAW [23]

ode GTAW. They found the latter decreased versus similar values of current in single-cathode welding.

Assuming the major arc force mainly arising from the plasma jet impinging on the anode surface, according to [23] the arc pressure can be derived from the law of momentum conservation:

$$
P=\frac{1}{2} \xi v^{2},
$$

where $P$ is the arc pressure; $\xi$ is the elemental plasma density; and $v$ is its velocity.

Using Maecker's [24] approach of relating the highest velocity $v_{\mathrm{c}}$ to the maximum current density in the arc centre, and assuming the plasma flow as «incompressible and inviscid»:

$$
v_{\mathrm{c}}=\sqrt{\frac{u_{0} I j}{2 \pi \xi}}
$$

where $u_{0}$ is the magnetic permeability of free space, and $j$ denotes the current density, one finally can achieve the relationship between arc pressure $P_{\mathrm{c}}$ and $j$ at the arc centre line [24]:

$$
P_{\mathrm{c}}=\frac{u_{0} I j}{4 \pi}
$$

representing the arc pressure as directly proportional to $I$ or $j$, respectively.

Applying expression (8), indicating the force attracting the arcs towards the centre, one can see the arc pressure increasing in the centre with rising arc currents or decreasing distance between the two cathodes employed. However, due to the split cathodes, both arcs are displaced from the centre, thus, likewise shifting the pressure maxima. According to [23] the force of attraction produces an arc overlapping, however, the resulting peak pressures are located off the centre and, hence, the final «coupling arc» pressure is dropped versus each single or «overlapping arc».

Figure 5, $a$ shows the visible arc appearance of a dual-cathode setup for 200 A total current, and Figure $5, b$ graphically plots the comparison of the distinct arc pressures produced.
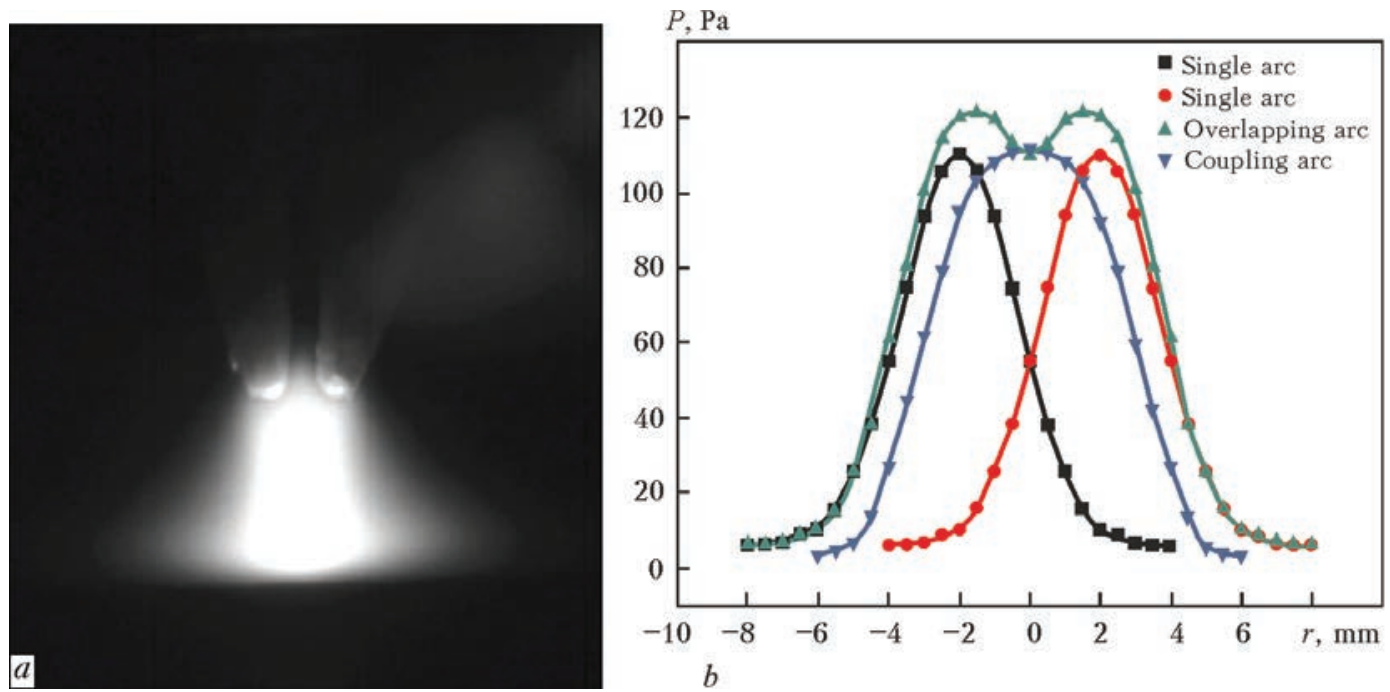

Figure 5. Visible overlapping of $2 \times 100 \mathrm{~A}$ arcs $(a)$, and comparison of single, overlapping and coupling arc pressures for 200 total current $(b)[23]$ 


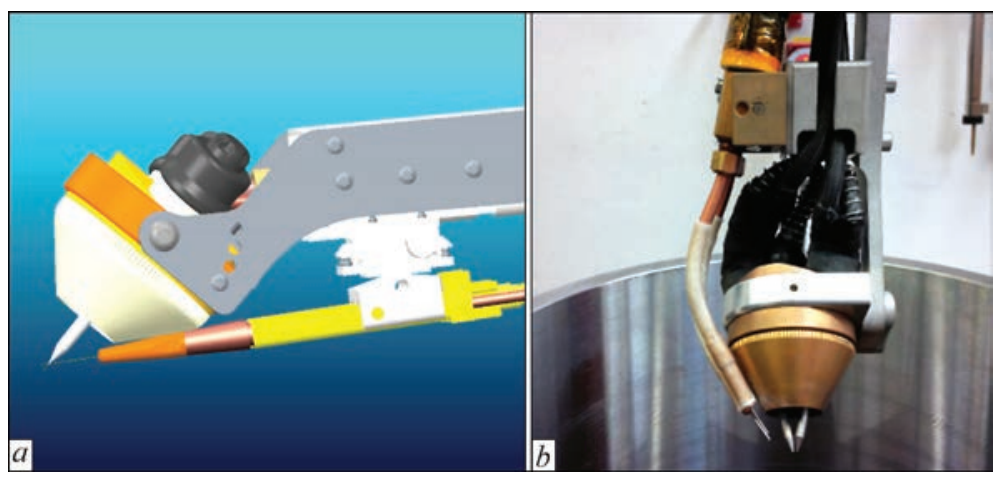

Figure 6. Schematic of single- $(a)$ and real part twin-hot-wire dual-cathode welding torch $(b)$ (FRONIUS SpeedClad ${ }^{\circledR}$ )

In the later work [25] Zhang et al. have applied the Fowler-Milne method to determine temperature distribution profiles in dual-cathode GTAW incorporating the influence of current, arc length and spatial electrode distance. Temperature maxima were found in the centre between both cathodes and current was evaluated increasing the temperature. Arc length was hardly affecting peak temperature but given the experimental setup, it was extending temperature distribution at the anodes. Wider cathode clearance was estimated decreasing the arc centre temperature. Martins [26] developed a dual-cathode welding torch based on commercial components for studying beneficial effects in preventing defects such as bead humping and undercut, while simultaneously increasing process performance.

Motivation. As mentioned above welding current plays a major part in order to increase process efficiency. Knowing dual-cathode GTAW applicable to beneficially preventing from weld defects at higher currents, it was aimed at developing an automation GTAW cladding system upon dual tungsten cathode technology.

Dual-cathode welding torch development. Severe arc interference can occur between both electrodes, capable of finally leading to process abortion due to cathode damage [26]. One of the most substantial technical requirements to meet in dual-cathode GTAW is highly precise and industrially practicable adjustment of both tungsten cathodes in one single welding torch. Arc interaction between both cathodes has to be assured sustainably suppressed, even for long lasting automated application, such as GTAW cladding. Finally, the development of components easily adaptable to automation hardware already available, such as the ETR ${ }^{\circledR}$ GTAW cladding system, was considered another essential target to achieve.

Figure 6 schematically shows the developed novel type dual-cathode torch head basically employed for fully mechanised single hot-wire or optionally twin hotwire GTAW application, the latter to further enhance weld deposition rates thus raising travel speed.

System configuration. Adequately assembled the system shall allow for single- and twin-hot-wire cladding. Figure 7, $a$ schematically depicts the configuration for performing the former process, and Figure 7, $b$ - the latter one.

Process mode and stability relevant components are interacting via hardware Local High Speed Bus (LHSB) interface, permitting to employ both pure constant direct current or to superimpose and synchronise current and wire feed motion. Both is of crucial importance in performing smooth start/stop sequences. In its practical configuration, equipped to $\mathrm{ETR}^{\circledR}$ column and boom system, the device physically appears (Figure 8). This Figure also shows the superimposed system controller, allowing sophisticated determination of welding paths to follow, according to the design of the part of interest.

Experimental. Given the novel dual-cathode GTAW cladding process and the equipment available, it was attempted to quantify differences and, if possible, to evaluate technological benefits to other weld overlay process variants. It needs mention that a distinct experimental approach was originally taken for achieving preliminary results. That is, single-

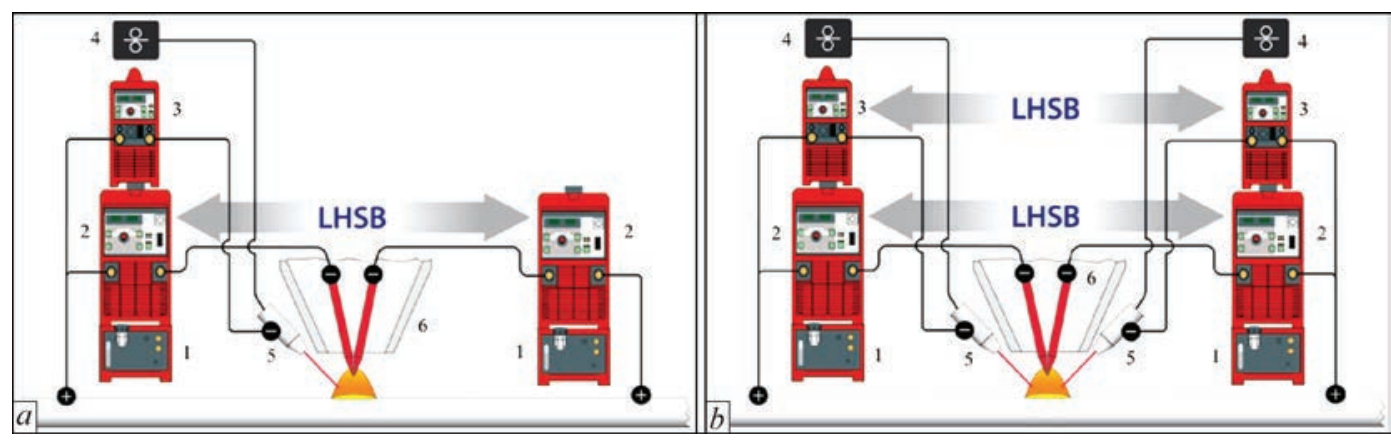

Figure 7. Schematic of dual-cathode single- $(a)$ and twin- $(b)$ hot-wire GTAW cladding system (SpeedClad ${ }^{\circledR}$ ): 1 - chiller; 2 - GTAW inverter power supply; 3 - hot wire inverter power supply; 4 - wire feeder; 5 - hot wire contact tube; 6 - dual-cathode torch 
and dual-cathode both twin- and single-wire cladding was conducted in the welding position easiest to apply, i.e. PA (AWS - 1F). Subsequently to that the experimental conditions (e.g. welding position) were tangibly aggravated for testing the novel advanced dual-cathode GTAW cladding process. Subsequently the experimental conditions for the application of the dual-cathode GTAW cladding were exacerbated, thereby to prove applicability given the regular industrial environment. Results were compared, and the quantitative differences were summarised.

Single-cathode twin-hot-wire GTAW cladding. Substrate specimens were produced from low carbon base metal S235 JR (according to Euronorm EN 10025) $50 \mathrm{~mm}$ thick. Surface was milled and cleaned applying ethyl alcohol prior to welding without preheating. Regular commercial FRONIUS systems and components have been applied, namely Magic Wave 5000 AC/DC GTAW inverter (500 A at $40 \%$ duty cycle), and for hot-wire cladding Transtig 2200 JOB GTAW inverter (220 A at $40 \%$ duty cycle) have been used as power supplies. The 6-axis KUKA articulated robot equipped with $4.5 \mathrm{~m}$ hose package + water-cooled TTW 4500 welding torch and superimposed HMI-T10CC system control unit were used for arc motion and process control, respectively. Argon ( $99.996 \%$ purity) as the shielding gas at flow rate of $121 / \mathrm{min}$ and $2 \%$ cerium oxide doped $3.2 \mathrm{~mm}$ diameter tungsten electrode ground to $60^{\circ}$ included angle were applied. Filler wire in both trial series was $1.2 \mathrm{~mm}$ nickel-based alloy UNS N06625 (AWS ER NiCrMo-3), «Böhler Nibas 625-IG». Filler metal specific density was $8.44 \mathrm{~g} / \mathrm{cm}^{3}$ [27].

All processes, i.e. single-cathode cold- and hotwire as well as dual-cathode twin-hot-wire cladding, were performed applying two layer and targeting at average layer thickness of about $2.5 \mathrm{~mm}$. According to industrial demands, the metallurgical quality of the second clad layer was evaluated through its iron content related to a specific distance from its surface. That is, $\leq 55 \% \mathrm{Fe}$ at $\leq 3 \mathrm{~mm}$ below the surface had to be consistently proved for meeting the requirements.

Single-cathode twin-hot-wire and dual-cathode single-hot-wire GTAW cladding. Table 1 states the preliminarily conducted welding trials using pulsed and constant straight polarity direct current.

Dual-cathode twin-hot-wire GTAW cladding. Commercial FRONIUS ETR ${ }^{\circledR}$ GTAW cladding system (Figure 8) was used comprising FCB 30003000/ML 700 Column and Boom paired with FCS

Table 1. Preliminary experimental data

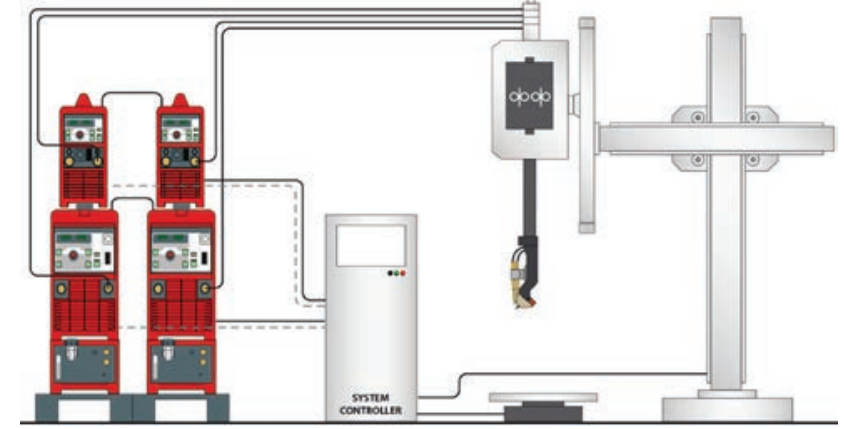

Figure 8. Schematic of dual-cathode GTAW cladding system $\left(\right.$ SpeedClad $^{\circledR}$ )

200-1000/ML 375 cross slide and novel TTHW $6000 \mathrm{M}$ SpeedClad ${ }^{\circledR}$ GTAW twin-hot-wire torch. The system was completed assembling two DC GTAW power supplies Transtig $5000 \mathrm{JOB}$ (500A at $40 \%$ duty cycle) and two hot-wire power supplies Transtig 2200 JOB, as well as superimposed system control unit FRONIUS FPA 9000.

Tube welded specimens of $155 \mathrm{~mm}$ diameter with wall thickness of $20 \mathrm{~mm}$, to simulate internal borehole cladding, were produced from low carbon S 235 JR parent metal. 30 beads were deposited in total applying welding position PC (AWS - 2F). Specimen surfaces were machined and cleaned using ethylene alcohol prior to welding. Consumables were similar to single-cathode hot-wire GTAW cladding, i.e. $1.2 \mathrm{~mm}$ UNS N06625 filler wire and argon of $99.996 \%$ purity. Gas flow rate was digitally controlled at $241 / \mathrm{min}$, and $2 \%$ cerium oxide doped $4.0 \mathrm{~mm}$ tungsten electrodes were used, ground to obtain $56^{\circ}$ included angle. Circumferential bead deposition was conducted employing $3.4 \mathrm{~mm}$ vertical lateral increment, and electrode gap was maintained constant deploying regular arc voltage control included in the ETR ${ }^{\circledR}$ system. Parts were manually preheated to $200{ }^{\circ} \mathrm{C}$ using oxyfuel torch $\left(\mathrm{C}_{3} \mathrm{H}_{8}+\right.$ $\mathrm{O}_{2}$ ). Interpass temperature was chosen $200{ }^{\circ} \mathrm{C}$. For the dual-cathode twin-hot-wire welds Table 2 depicts a WPS excerpt of the essential variables used.

The Table reveals that both wire feed rate to hot-wire current ratio and travel speed have been maintained constant throughout both trial series. In pulsed welding the ratio between pulsed and background cycle defines the height of the output current. Adjusting background and pulsed current time balanced to each other and given the parameters chosen the pulsed process shows slightly higher mean welding current.

Results. Single-cathode (twin-wire) and $d u$ al-cathode (single-wire) cladding. Figure 9 shows

\begin{tabular}{|c|c|c|c|c|c|c|c|c|c|c|}
\hline Process & $I_{\mathrm{p}}, \mathrm{A}$ & $I_{\mathrm{w}}, \mathrm{A}$ & $I_{\mathrm{b}}, \mathrm{A}$ & $U_{\text {mean }}, \mathrm{V}$ & $v_{\mathrm{w} . \mathrm{f}}, \mathrm{cm} / \mathrm{min}$ & $v_{\mathrm{h} . \mathrm{f}}, \mathrm{cm} / \mathrm{min}$ & $t_{\mathrm{p}}, \mathrm{ms}$ & $t_{\mathrm{b}}, \mathrm{ms}$ & $f, \mathrm{~Hz}$ & $I_{\text {h.w }}, \mathrm{A}$ \\
\hline Single-cathode twin-hot-wire & 320 & - & 280 & 13.5 & $1.6^{*}$ & 32 & 200 & 200 & 2.5 & 70 \\
\hline Same & 350 & - & 300 & 14.2 & $2.6^{*}$ & 50 & 150 & 150 & 3.3 & 70 \\
\hline Dual-cathode single-hot-wire & - & $450^{*}$ & - & 12.1 & 7.6 & 80 & - & - & - & 190 \\
\hline
\end{tabular}


Table 2. Experimental data for dual-cathode twin-hot-wire welding (FRONIUS SpeedClad ${ }^{\circledR}$ )

\begin{tabular}{|c|c|c|c|c|c|c|c|c|c|}
\hline Welding current & $I_{\mathrm{w}}, \mathrm{A}$ & $I_{\mathrm{b}}, \mathrm{A}$ & $U_{\text {mean }}, \mathrm{V}$ & $v_{\mathrm{w} . \mathrm{f}} \mathrm{m} / \mathrm{min}$ & $v_{\mathrm{h} . \mathrm{w}}, \mathrm{cm} / \mathrm{min}$ & $t_{\mathrm{p}}, \mathrm{ms}$ & $t_{\mathrm{b}}, \mathrm{ms}$ & $f, \mathrm{~Hz}$ & $I_{\mathrm{h} . \mathrm{w}}, \mathrm{A}$ \\
\hline DC constant & 370 & - & 10.4 & 4.8 & 120 & - & - & - & 240 \\
\hline Pulsed current & 430 & 370 & 11.0 & 5.0 & 120 & 70 & 70 & 7.1 & 250 \\
\hline
\end{tabular}

the macrosections of deposits for single-cathode twin wire and dual-cathode single-wire cladding.

No significant visual variation appears in the penetration profile between pulsed single-cathode twin-wire and constant DCSP dual-cathode single-wire cladding sequence. Iron content was found safely below $5 \%$ for all three welds. Deposition rates achieved were respectively 1.83 (32) and $2.98 \mathrm{~kg} / \mathrm{h}$ $(50 \mathrm{~cm} / \mathrm{min})$ for single-cathode twin-wire, and $4.23 \mathrm{~kg} / \mathrm{h}(80 \mathrm{~cm} / \mathrm{min})$ for dual-cathode single-wire GTAW cladding.

Dual-cathode (twin-wire) constant and pulsed $D C S P$ cladding. Figure 10, $a$ as an overview reveals the compact dual-cathode head processing inside the $155 \mathrm{~mm}$ diameter pipe specimen, and Figure 10, $b$ shares an idea of high surface layer quality obviously achieved applying this novel method.

According to the parameters in Table 2, Figure 11 represents the macrosections of dual-cathode deposits as subjected to EDX analysis.

For all welding sequences Figure 12 shows the clad quality indicating iron content over the distance of $3 \mathrm{~mm}$ below the layer surface (Oxford INCA Energy/
PM 55 system). Deposition rates employing dual-cathode twin-hot-wire were found considerably increased, respectively leading to about $5.6 \mathrm{~kg} / \mathrm{h}$ for constant DCSP and about $5.7 \mathrm{~kg} / \mathrm{h}$ for pulsed DCSP. Greater homogeneity is found for higher current-higher travel speed trials. However, the lowest travel speed of $32 \mathrm{~cm} / \mathrm{min}$ is prone to greater noise in the surface elemental distribution.

Figure 13 represents from EDX analysis the elemental surface layer chemistry focusing on the essential alloying elements particularly in charge of the deposited layer corrosion resistance. Also, for comparison, it involves the analysis of the filler wire employed. Similar elemental distribution can be found in the second layer especially in using the novel dual-cathode twin-hot-wire GTAW cladding method, with minimal differences to the consumable chemistry, exceptionally, of course, the iron content deliberately decreased in the wire.

Based upon theoretical considerations on varying impacts depending maybe on varying orientation angles of two cathodes, i.e. from longitudinal to normal, related to welding direction, additional studies were conducted using the dual-cathode system for both cases.

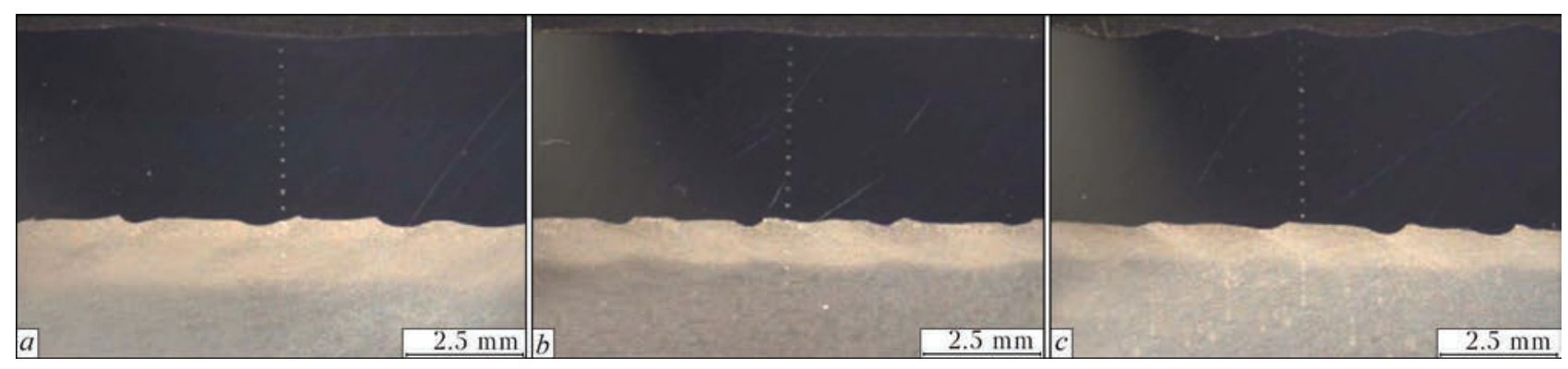

Figure 9. Macrosection of deposits for single-cathode twin-hot-wire cladding at $32(a)$ and $50(b) \mathrm{cm} / \mathrm{min}$ travel speed, and dual-cathode single-hot-wire cladding at $80 \mathrm{~cm} / \mathrm{min}(c)$

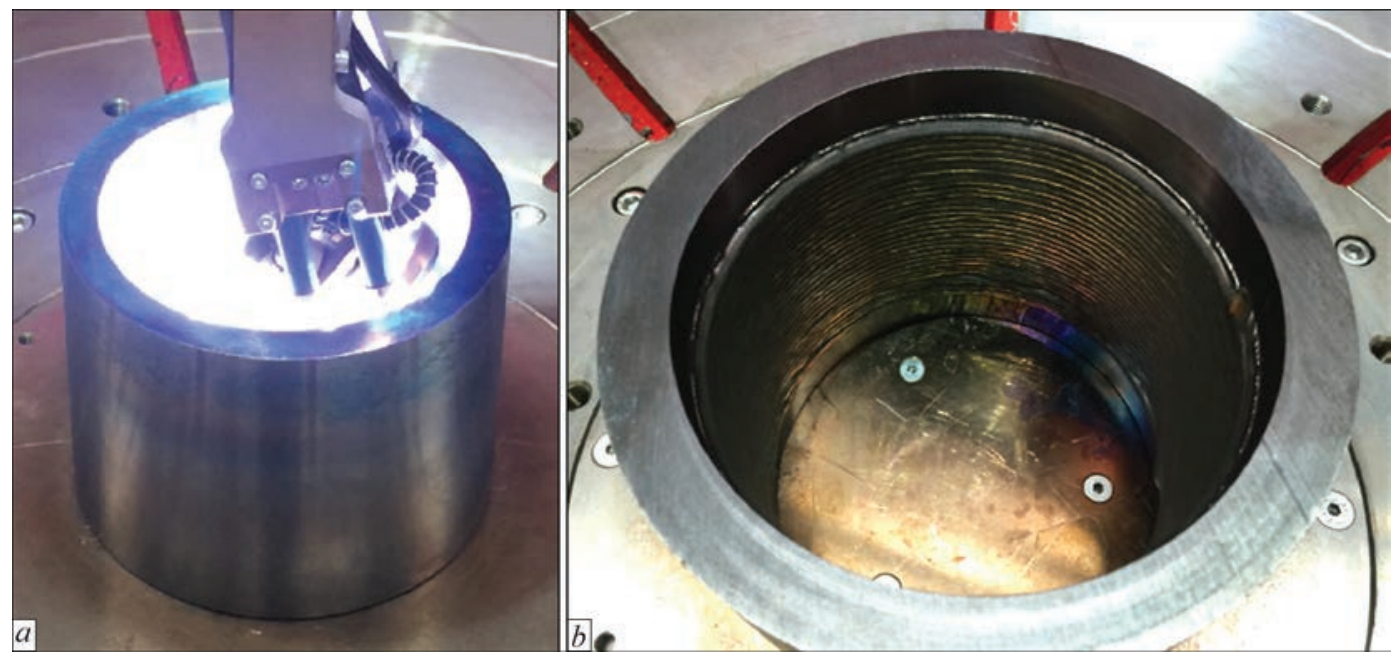

Figure 10. Dual-cathode head (SpeedClad $\left.{ }^{\circledR}\right)$ during cladding $(a)$, and layers deposited using pulsed process $(b)$ 


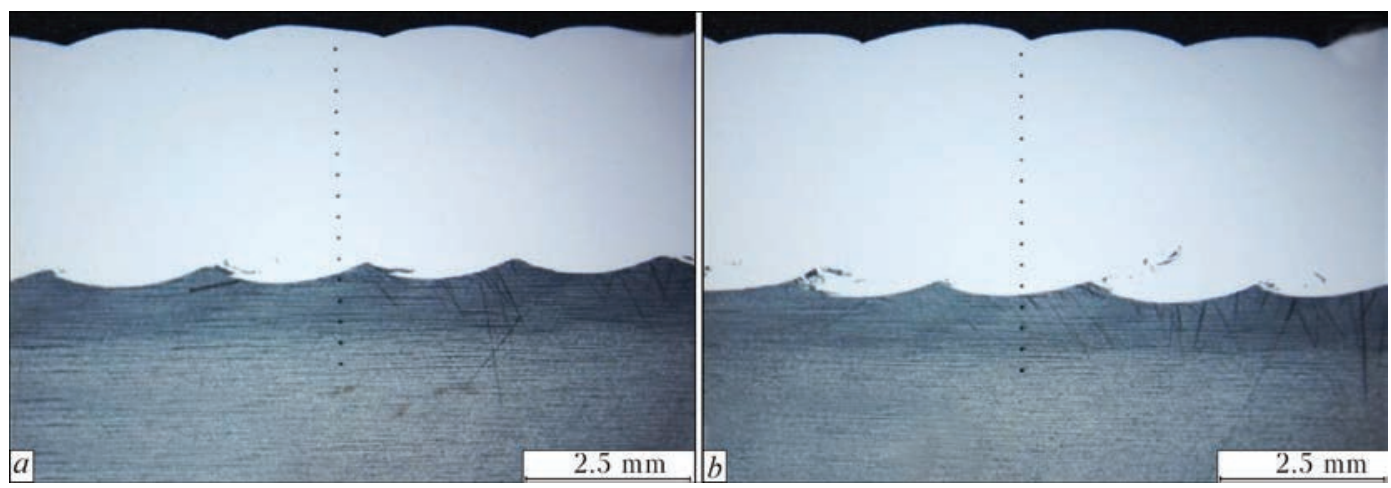

Figure 11. Macrosection of deposits obtained with dual-cathode twin-hot-wire at constantly supplied $(a)$ and pulsed $(b)$ direct current at travel speed of $120 \mathrm{~cm} / \mathrm{min}$ in welding position PC

As already investigated and numerically modelled by Leng et al. [23] tangible differences could be approved.

Figure 14, $a$ shows the macrosection for the former configuration, i.e. tungsten electrodes arranged longitudinally to welding direction, while Figure $14, b$ indicates the electrodes twisted by $90^{\circ}$ to obtain them arranged normal to welding progression.

The effective influence between both setups can be readily noticed. It is suggested necessary as such to further devote effort in establishing reliable quantitative data on influence of differently twisted electrodes related to weld metal dilution and elemental distribution.

Discussion. The results achieved from the experiments accomplished are suggested valuable due to allowing quantitatively comparing regular high performance GTAW cladding processes, i.e. twin-hot-wire GTAW with a novel approach referred to as dual-cathode GTAW.

The latter can be either used employing a single or two filler wires leading to significantly higher deposition rates. The welding trial matrices chosen, distinguished in a preliminary phase using a dual-cathode prototype equipment and a final period particularly focusing on industrial application and targeted at achiev-

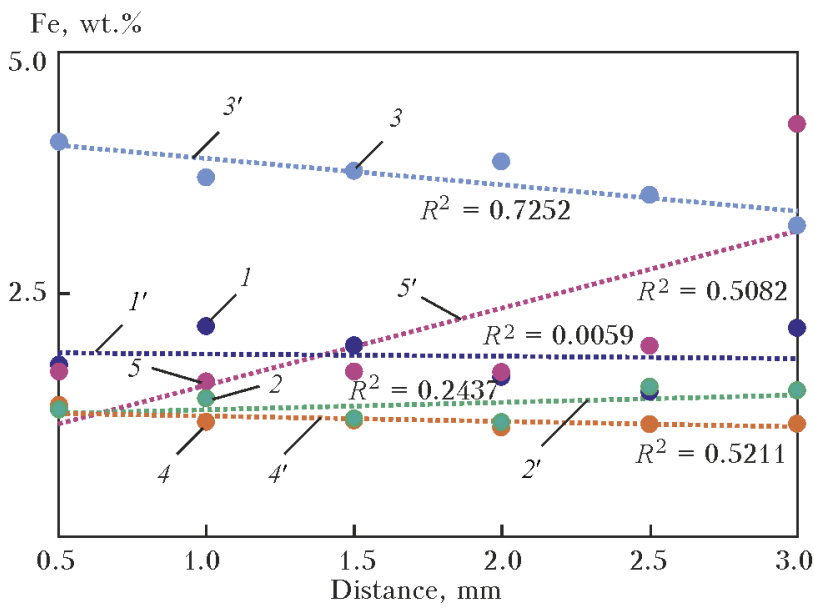

Figure 12. Iron content versus distance below clad layer surface for process applied: $1,1^{\prime}$ - single-cathode, twin-hot-wire, $32 \mathrm{~cm} / \mathrm{min}$; 2, 2' - dual-cathode, single-hot-wire, $80 \mathrm{~cm} / \mathrm{min} ; 3,3^{\prime}-\mathrm{du}-$ al-cathode, dual-hot-wire, pulsed DC, $120 \mathrm{~cm} / \mathrm{min} ; 4,4^{\prime}$ - single-cathode, twin-hot-wire, $50 \mathrm{~cm} / \mathrm{min} ; 5,5^{\prime}$ - dual-cathode, dual-hot-wire, constant DC, $120 \mathrm{~cm} / \mathrm{min}$

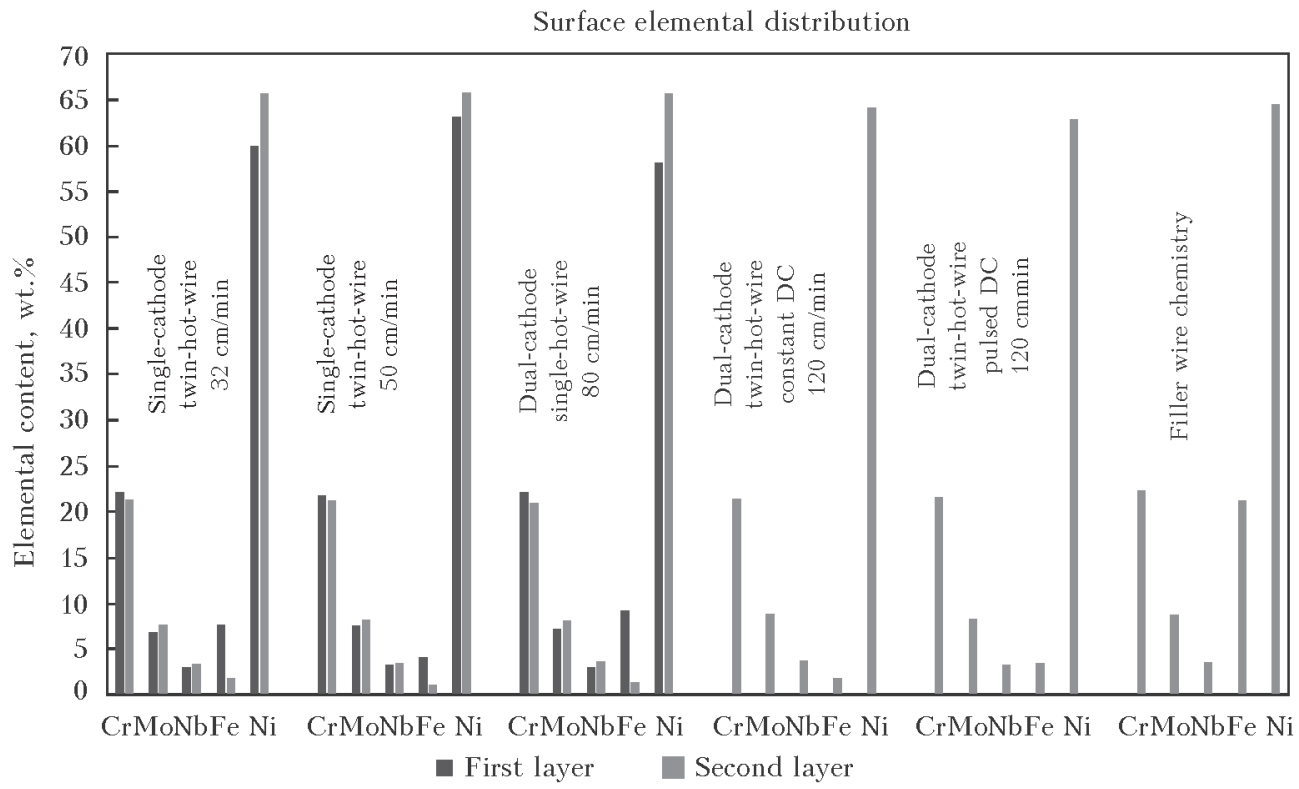

Figure 13. Elemental distribution on clad layer surface compared with filler wire chemistry (analysis for dual-cathode twin-wire deposits was conducted only for the second layer) 


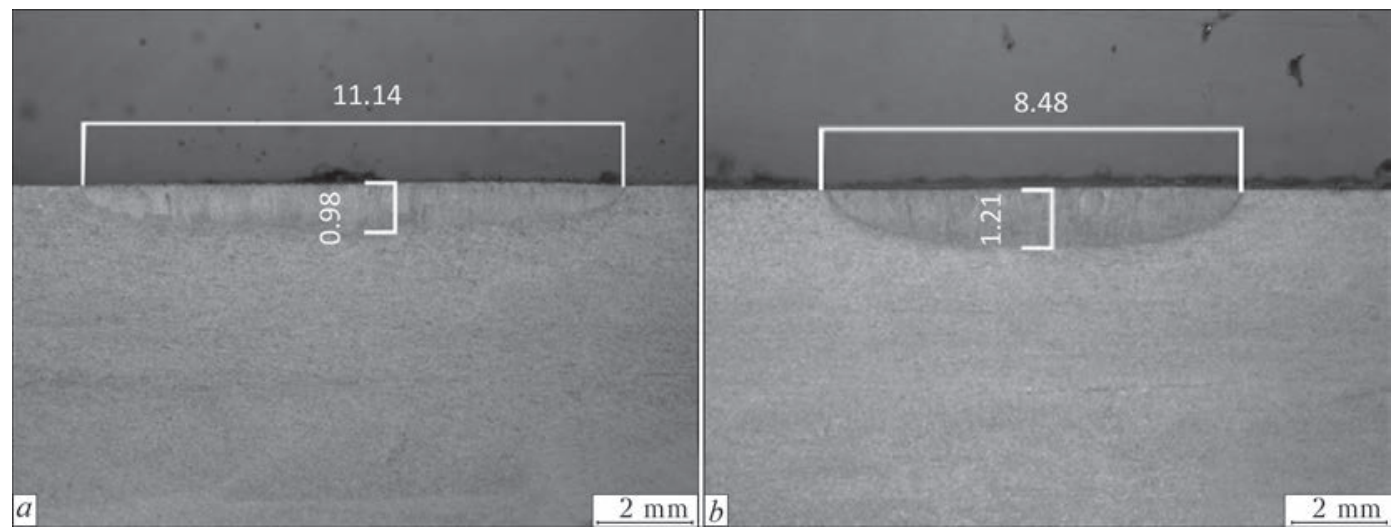

Figure 14. Results of dual-cathode GTAW autogenously employed with electrodes adjusted longitudinal (a) and normal to welding direction $(b)$ (cathode diameter of $4.0 \mathrm{~mm}$; total welding current of $300 \mathrm{~A}(2 \times 150 \mathrm{~A})$; cathode clearance of about $2.0 \mathrm{~mm}$; electrode-to-workpiece distance of $4.0 \mathrm{~mm}$; and travel speed of $40 \mathrm{~cm} / \mathrm{min}$ )

ing meaningful assessment on process performance and quality aspects to meet, are supposed showing the investigations of other researchers approved.

Although focusing on fusion welding, multiple cathode GTAW has been investigated by Norrish [21], Yamada [18, 19], Kobayashi [20] et al. However, we could find the novel developed method also capable of increasing welding speed, as to overcome weld defects and rising productivity in GTAW cladding. Yet outstanding in quantitative approval and, hence, only qualitatively suggested at this stage, we suppose that the fundamental mechanism of both low dilution and eliminating weld defects (undercut) arises from a lower arc pressure at the same total current versus single-cathode welding, connected to the specific cathode arrangement in the welding head developed. It needs mention though that the results derived by other researchers considerably differ to each other. That is Kobayashi et al. [20] found respectively arc pressures of about $1500 \mathrm{~Pa}$ for a single cathode (200 A welding current $+2 \mathrm{~mm}$ 《arc length») and about $250 \mathrm{~Pa}$ for their dual-cathode arrangement; for the same total current and similar experimental setup Zhang et al. [22] and Leng et al. [23] determined maximum arc pressures of about 500 (single-cathode) and about $95 \mathrm{~Pa}$ (dual-cathode).

Apart from these differences we nonetheless suggest the relationship between welding current height and arc pressure, as e.g. postulated by Adonyi et al. [15] and Rokhlin and Guu [16], also applicable to GTAW hot-wire cladding; at least for the experimental conditions described in this paper. This is due to the higher dilution ratios observed when charging the dual-cathode arrangement with pulsed direct current (thereby increasing the mean current) versus constantly applied DCSP.

Despite achieving a higher mean current the deposition rate was found relatively little raised with the pulsed sequence, which is suggested explainable by the only slightly increased wire feed rate versus the constant current sequence ( 5.0 versus $4.8 \mathrm{~m} / \mathrm{min}$ ). Considering further dilution ratios - found raised for pulsed current GTAW and correspondingly the constant ratio between wire feed rate and hot-wire current one may suggest though the results of Shinozaki et al. [14] as approved; supposing that filler wire melting is mainly influenced by hot-wire current instead of being a function of the arc current. However, we suggest that further work appears required in this conjunction to assess both these assumptions as well as evaluating the relationship between wire feed rate, hotwire current and arc current.

Given our experiments (see Figure 14), i.e. changing the dual-cathode orientation angle related to welding progression, we suggest the considerations of Leng et al. [23] on varying current density and temperature fields around the cathodes, valuably contributing to future research, especially in connection to dual-cathode twinhot-wire GTAW cladding. Hence, and although not yet practically proved by the investigations dealt with in this paper, it is supposed that both weld dilution and deposited bead height can be positively affected incorporating the dual-cathode orientation angle, hereby further to improve weld metal elemental distribution and secondary properties, e.g. clad layer corrosion resistance.

\section{Conclusions}

From the experiments explained in this paper we can draw the following conclusions:

- single-cathode gas tungsten arc hot-wire cladding employing two wires of $1.2 \mathrm{~mm}$ diameter, and typical UNS N06625 chemistry was found reliably leading to welding results safely meeting industrial requirements;

- novel dual-cathode GTAW system was compared with the results obtained in single-cathode GTAW cladding;

- novel system was proved capable of considerably raising welding performance, i.e. deposition rate and travel speed, and nonetheless to safely meet all industrial requirements;

- iron content, as the qualitative indicator for clad layer quality, was quantified reliably remaining below 
threshold when employing the dual-cathode GTAW cladding system both single-wire (welding position $\mathrm{PA}$ ) and twin-wire (welding position PC);

- relationship between welding current height and arc pressure appears approved and applicable also to an experimental setup as used in this investigation;

- although not quantitatively approved in this investigation, the reduced arc pressure is supposed the major factor in dropping the depth of penetration when employing dual-cathode GTAW cladding, hereby considerably reducing the dilution ratio versus single-cathode GTAW cladding at similar welding current;

- hot-wire current is suggested mainly affecting deposition rate versus arc current and as such our results appear to confirm the findings of other researchers;

- experimental results on varying dual-cathode orientation angle related to welding direction (longitudinal or normal) are suggested approving theoretical considerations of other researchers and are considered valuable for future work;

- dual-cathode GTAW is supposed finally to future sustainably and reliably broadening the range of high quality cladding applications required complying with «zero-defect» criteria.

Acknowledgements. The authors are grateful to Mr. Emre Güneruz, Mr. Franz Bichler and Mr. Andreas Bauer, all with FRONIUS International, who have performed the experimental work, as well as to Mr. Uwe Kroiss of FRONIUS International's $R \& D$ department for conducting the dual-cathode orientation trials.

1. Egerland, S. (2010) Controlled GMA welding processes prove applicability for high-quality weld overlay. In: Welding and Repair Technology for Power Plants: Proc. of 9th Int. EPRI Conf. (2010 June 23-25, Fort Myers). Palo Alto: Electric Power Research Institute.

2. Egerland, S. (2009) Status and perspectives in overlaying under particular consideration of sophisticated welding processes. Quart. J. JWS, 27(2), 50-54.

3. Egerland, S., Helmholdt, R. (2008) Overlaying (cladding) of high temperature affected components by using the cold metal transfer process. In: Safety and reliability of welded components in energy and proc. industry, 327-332. Graz: Verlag der Technischen Universität.

4. Freeman, N.D., Manz, A.F., Saenger, J.F.Jr. Inventors; Union Carbide Corp, assign. Method for depositing metal with a TIG arc. Pat. US 3483354. Publ. Dec. 9, 1969.

5. Manz, A.F., Norman, R., Wroth, R.S. Inventors; Union Carbide Corp, assign. Electric arc working with hot wire addition. Pat. US 3163743. Publ. Dec. 29, 1964.

6. Manz, A.F. Inventors; Union Carbide Corp, assign. Consumable electrode arcless electric working. Pat. US 3122629A. Publ. Feb. 25, 1964.

7. Hori, K., Myoga, T., Shinomiya, M. et al. Inventors; Kaisha BHK assign. Semi-automatic hot wire TIG welding equipment. Pat. US 4801781. Publ. Jan. 31, 1989.

8. Mizuno, T., Shimizu, T. Inventors; Kaisha MDK assign. Hot wire welding system. Pat. US 4464558A. Publ. Aug. 7, 1984.
9. Goldsberry, C. (2007) Hot-wire TIG: Not new but gaining appeal. http://weldingdesign.com/ archive/hot-wire-tig-notnew-gaining-appeal

10. Manabe, Y., Wada, H., Zenitani, S. (2000) Investigation on TIG welding using 2 filler wires with electromagnetically controlled molten pool process in horizontal position. Quart. J. JWS, 8(1), 40-50; http:// dx.doi.org/10.2207/qjjws.18.40

11. Hori, K., Watanabe, H., Myoga, T. et al. (2004) Development of hot wire TIG welding methods using pulsed current to heat filler wire: Research on pulse heated hot wire TIG welding processes. Welding Int., 18(6), 456-468; http://dx.doi. org/10.1533/wint.2004.3281

12. Ueguri, S., Tabata, Y., Shimizu, T. et al. (1986) A study on control of deposition rate in hot-wire TIG welding. Quart. J. JWS, 4(4), 678-684; http://dx.doi. org/10.2207/qjjws.4.678

13. Yamamoto, M., Shinozaki, K., Myoga, T. et al. (2008) Development of ultra-high-speed GTA welding process using pulse-heated hot-wire. In: Pre-Prints of the 82nd Nat. Meeting of JWS, 228-229.

14. Shinozaki, K., Yamamoto, M., Nagamitsu, Y. et al. (2009) Melting phenomenon during ultra-high-speed GTA welding method using pulse-heated hot-wire. Quart. J. JWS, 27(2), 22-26; http:// dx.doi.org/10.2207/qjjws.27.22s

15. Adonyi, Y., Richardson, R., Baeslack, W. (1992) Investigation of arc force effects in subsurface GTA welding. Welding $J$., 71(9), 321-330.

16. Rokhlin, S., Guu, A. (1993) A study of arc force, pool depression, and weld penetration during gas tungsten arc welding. Ibid., 72(8), 381-390.

17. Mendez, P., Eagar, T. (2003) Penetration and defect formation in high-current arc welding. Ibid., 82(10), 296-306.

18. Yamada, M. (1998) Development of high efficiency TIG welding method. 1st Rep. of JWS, 63, 24-25.

19. Yamada, M., Tejima, A. Inventors; Ishikawajima-Harima Heavy Industries Co. assign. TIG welding apparatus and method. Pat. US 6982397. Publ. Jan. 3, 2006.

20. Kobayashi, K., Nishimura, Y., Iijima, T. et al. (2013) Practical application of high efficiency twin-arc TIG welding method (SEDAR-TIG) for PCLNG storage tank. Welding in the World, 48(7/8), 35-39.

21. Norrish, J. (2006) Advanced welding processes. Cambridge: Woodhead Publ.

22. Zhang, G., Leng, X., Lin, W. (2006) Physics characteristic of coupling arc of twin-tungsten TIG welding. Transact. of NonFerrous Metals Soc. of China, 16(4), 813-817.

23. Leng, X., Zhang, G., Wu, L. (2006) The characteristic of twin-electrode TIG coupling arc pressure. J. Phys. D: Appl. Phys., 39(6), 1120-1126; http://dx.doi.org/10.1088/00223727/39/6/017

24. Maecker, H. (1955) Plasmaströmungen in Lichtbögen infolge eigenmagnetischer Kompression. Zeitschrift für Physik, 141(1), 198-216.

25. Zhang, G., Xiong, J., Gao, H. et al. (2012) Effect of process parameters on temperature distribution in twin-electrode TIG coupling arc. J. Quantitative Spectroscopy \& Radiative Transfer, 113(15), 1938-1945; http://dx.doi.org/10.1016/j. jqsrt.2012.05.018

26. Martins, É.A. (2010) Avaliação da soldagem tig autógena duplo cátodo twin Tig [trabalho de graduação]. Florianópolis: Universidade Federal de Santa Catarina .

27. (2006) Special Metals Corporation. Inconel alloy 625. Special Metals: Material Manufacturer Data Sheet.

Received 15.01.2016 